\title{
Editorial: \\ Quantity versus Quality and Changes in Scholarly Communication
}

\section{Inge Angevaare}

inge.angevaare@kb.nl

Legendary Turkish hospitality and abundant sunshine framed this year's Annual General Conference at Koç University, Istanbul, which provided the content for this issue of LIBER Quarterly.

Two debates caught my attention in particular: the continuing discussion within the community on whether to digitise for quantity or quality; and the impact of online availability on scholarly communication in general.

The opening speech by Ricky Erway (RLG/OCLC), entitled 'Shifting Gears: Supply and Demand: Special Collections and Digitisation', must have been perceived by quality-minded librarians as downright provocative in its premise that 'quantity has a quality all of its own'. 'Scale matters and fragmented small-scale activities do not map well onto behaviours in a web environment' (both quotes by Lorcan Dempsey). Erway went on to say that researchers will benefit most from large quantities of materials on the web rather than just a few pictures perfectly digitised. She stressed the importance of focusing on building infrastructures rather than organising isolated projects, implying that it is context that matters - not just the traditional library context of perfect bibliographic descriptions, but the context of other, related content, only one or two mouse-clicks away.

LIBER itself is intensifying its role in building unifying infrastructures, as is demonstrated by Paul Ayris's contribution on the European digital information landscape. From TEL, via Europeana, to LIFE and joint digitisation workshops with Eblida, LIBER is actively engaged in the European information 
infrastructure. Zooming in on 'Charlie', Ayris's model library user, Ayris suggests that mass digitisation and $24 / 7$ availability help to redefine what a modern research library should be like.

Sijbolt Noorda, President of the Dutch Research Universities Association, had something to say about this, although unfortunately he could not make his write-up available for LIBER Quarterly. He asserted that digitisation has had quite a big impact on research itself, that it has had some impact on administration, but the uptake in teaching and learning was 'slow and seldom straight'. Noorda went on: 'Very few research libraries developed into sustainable integrated e-support services for research and teaching \& learning.' Noorda said that such services should be attuned to researching methods in the different disciplines, which of course complicates easy solutions. One Dutch research librarian I spoke to suggested that Noorda might perhaps be judging too soon: her library is actively involved in developing just such services.

Noorda had another interesting point to make on peer review of scholarly output, which he deems essential for the reputation game. At present it is mainly publishers who organise such review and Noorda said: 'I cannot imagine anyone else taking over that task with the same impact, let alone consortia of research libraries.' He pleaded the case of open cooperation between academia and publishers and a fair reward for publishers' efforts.

Unsurprisingly, David Prosser of SPARC Europe, took another view at the scholarly communication cycle: 'The library could begin to take on some roles involved in the formal publication of research — through organising peer review, alerting services, searching tools, etc. They could create and host virtual research environments that take advantage of Web 2.0 tools to fulfil the e-science needs of researchers. Also they can take responsibility for the longterm preservation of an institution's intellectual output (theses, data, publications, etc.). These new roles will require the library to reposition itself in the scholarly communication value chain and develop new business models.'

An alternative model in which both the publishers' responsibility for peer review and the market's demand for open access might be reconciled, is presented by the SCOAP ${ }^{3}$ initiative described by Anne Gentil-Beccot and Ralf Schimmer. Although perhaps not applicable to every discipline, it is definitely a model that merits librarians' close attention. 
A last word about this year's host country Turkey. A staggering 44 percent of the population is under the age of 25, causing universities and libraries to be built at an astounding rate: within the last two years, 40 universities have been founded alone. With little or no traditional printed collections, these new libraries show exploding e-journal usage rates, which put them right in the middle of the movement to shape the research library of the twenty-first century. 